IP Periodica Polytechnica Civil Engineering

59(3), pp. 43344402015

DOI: $10.3311 /$ PPci.7848

Creative Commons Attribution (1)

RESEARCH ARTICLE

\section{Dynamic Response of a Pendulum Isolator System under Vertical and Horizontal Earthquake Excitation}

\author{
Alireza Jamalzadeh, Majid Barghian
}

Received 02-12-2014, revised 30-03-2015, accepted 18-05-2015

\begin{abstract}
The paper studies a pendulum isolator. This isolator has a spherical surface which is placed on the foundation and it has an arm which is connected to the column of the building as a hinge. When the height of the arm is less than the curvature radius of the spherical surface, and a small movement is applied on it, a restoring force will be applied to the isolator. In this paper the effect of horizontal and vertical component of seismic load was studied. The dynamic equation of motion was obtained for the pendulum isolator under horizontal and vertical accelerations of seismic loads. The equation was solved by step time integration method. The comparison of the results of horizontal component effect and the combined effect of horizontal and vertical components on the isolator showed that the vertical component effect increased the isolator horizontal displacement response and increased the isolator horizontal acceleration.
\end{abstract}

\section{Keywords}

base isolation $\cdot$ vibration control $\cdot$ pendulum isolator $\cdot$ earthquake vertical acceleration effect $\cdot$ combined horizontal and vertical components effects of earthquake

\section{Alireza Jamalzadeh}

Department of Structural Engineering, Ahar Branch, Islamic Azad University, Ahar, Iran

e-mail: a-jamalzadeh@iau-ahar.ac.ir

\section{Majid Barghian}

Department of Structural Engineering, Tabriz University, Tabriz, Iran e-mail: barghian@tabrizu.ac.ir

\section{Introduction}

In traditional seismic design approach, strength of the structure was suitably adjusted to resist the earthquake forces.

The earthquakes in the recent past have provided enough evidence of performance of different type of structures under different earthquake conditions. This has given the idea to engineers to use different type of techniques to save the structures from the earthquakes. Base isolation technique is one of those.

By isolating a building from its foundation, the earth movement transmission rate to a building is limited; therefore the hazards of earthquake to a structure are considerably reduced [1].

The main purpose of the base isolation device is to attenuate the horizontal acceleration transmitted to the structure. All the base isolation systems have certain features in common. They have flexibility and energy absorbing capacity. The main concept of base isolation is to shift the fundamental period of the structure out of the range of dominant earthquake energy frequencies and increasing the energy absorbing capability.

Different methods have been proposed for base isolation [2] and different new methods have been suggested by researchers. Presently base isolation techniques are mainly used in different types such as:

a) Mud layer below the structure, b) Flexible first storey, c) Roller bearings in foundations, d) Rubber layer as foundation support, e) Lead rubber bearing system, f) Resilient - friction base isolation system, g) Electric de-France system, h) Sliding resilient- friction system, i) High damping rubber bearing and so on.

Each of them has advantage and limitation. For example, Rubber bearings are suitable for buildings that are rigid and for masonry or reinforced concrete construction of up to seven stories. For this sort of building, uplift on the bearings will not occur and wind load will be unimportant.

A base isolation was used for the tomb of Cyrus (ancient Persian king) (about 2600 years ago) by using big stones without mortar above the ground and under the tomb. The tomb is still standing (Fig. 1). Fig. 2 shows a rubber bearing used in a building.

In a paper, Barghian and Shahabi [3] proposed a new method 
of isolation. They proposed bases which their shapes were a part of a sphere and each base had an arm that was attached and fixed perpendicularly to the concave surface. The other end of arm was attached as pin-ended joint to the column of the building. A sample base isolation studied in this research is shown in Fig. 3. The height of base arms must be less than sphere radius to produce restoring system force. In this system, the created eccentricity - between weight force and reaction force directions causes a moment. The moment action is the restoring force that intends to return back the system to the initial position. Barghian and Shahabi solved the motion equation of one-degree of freedom for this isolator under earthquake horizontal component. The results showed that the method was very effective in reducing the earthquake effect.

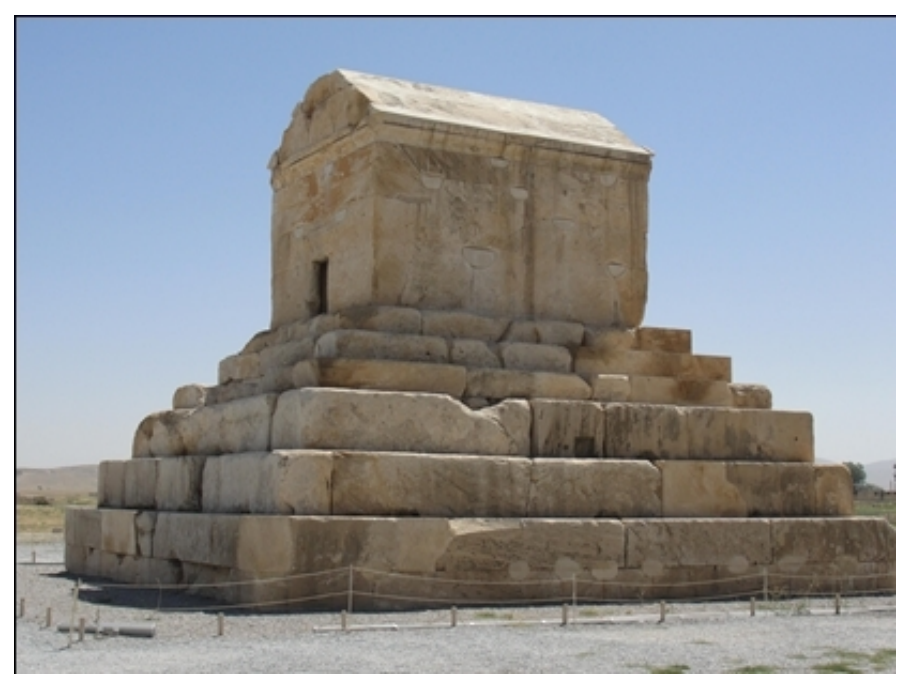

Fig. 1. A base isolation used for the tomb of Cyrus, in Iran

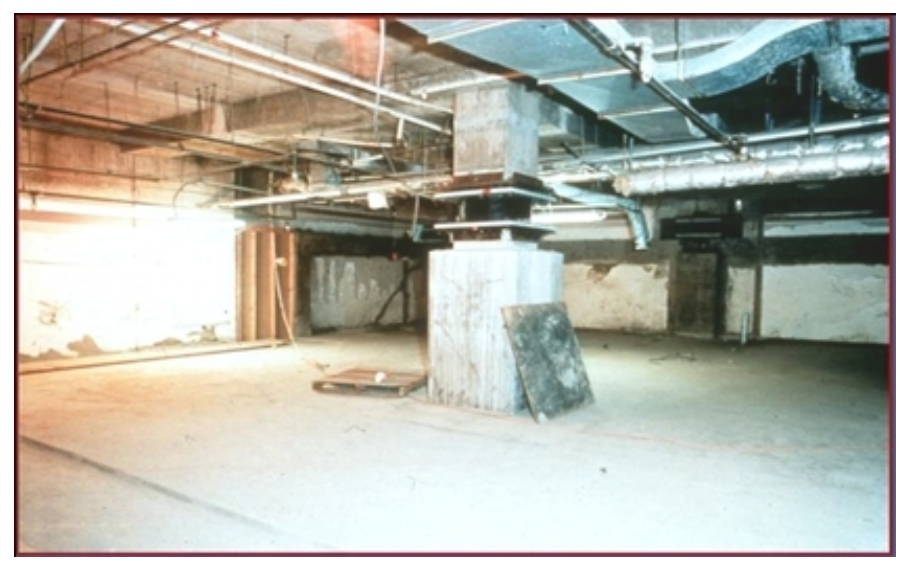

Fig. 2. A base isolation used for a building

Lu and Hsu [4] quoted that near-fault earthquakes may result in excessive isolator displacement for a conventional isolation system, and consequently lead to an oversized isolator design. To reduce the problem, seismic isolation using variablefrequency rocking bearings (shown in Fig. 4), were investigated experimentally by Lu and Hsu [4]. A full-scale steel frame isolated was tested in their work by using a shaking table. The test results showed that their system was able to effectively sup-

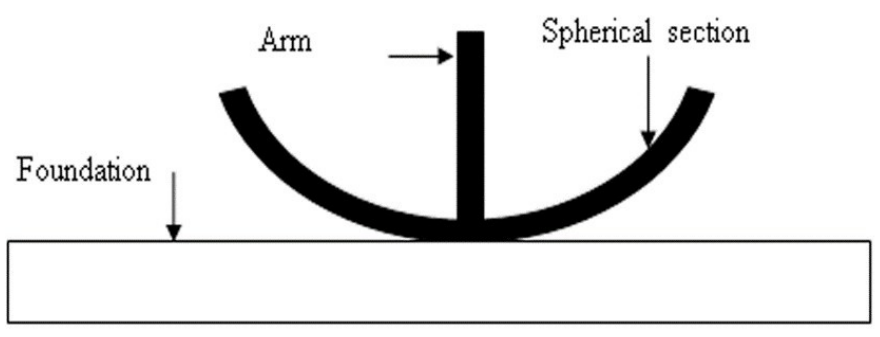

Fig. 3. A cross-section of pendulum base [3]

press the excessive isolator displacement induced by a near-fault earthquake.

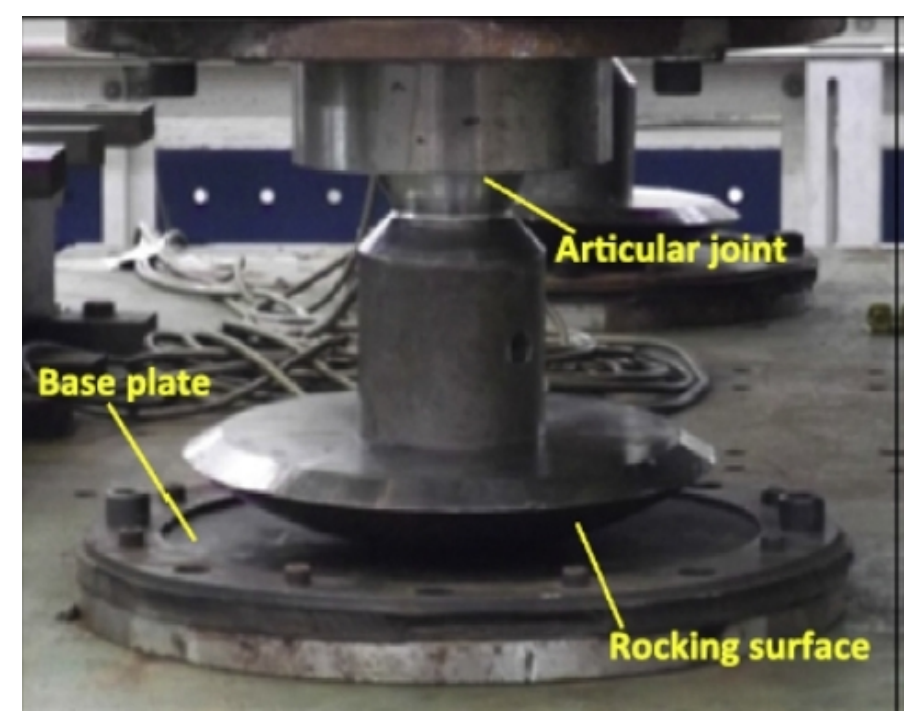

Fig. 4. A prototype bearing in tests used by $\mathrm{Lu}$ and Hsu [4]

The joint connection in Fig. 4 is similar to the one which was used by Barghian and Shahabi [3] and the one which is assumed in the present research.

Some researchers have suggested using isolation systems with variable mechanical properties, so the isolation systems may be adaptive to a wider range of earthquakes with different characteristics. The adaptability of variable isolation systems is usually achieved with three different approaches: active, semi-active and passive. In the first two, an active [5] or semi-active device [6] is incorporated into a conventional isolation system, and such devices act as a supplementary part of the isolation system that provides an efficient adaptive force, so the isolation performance of the whole system can be greatly improved. Nevertheless, both active and semi-active systems require sensing, actuation and computational units, so they may be more complicated and require more maintenance work than a passive one. For these reasons, variable isolation with fully passive devices is considered to be more reliable [7].

Ismail $m$. and et. al. [8] introduced a new isolation device known as (Roll-N-Cage) RNC isolator. They investigated and tested their isolator on a cable-stayed bridge model. The efficiency evaluation of RNC isolator device for the seismic protection of cable-stayed bridge was evaluated by Domaneschi, $m$. and et. al. [9]. 
Earthquake waves are propagated in all directions of earth so that the movements can be assumed as three transmission components and three rotational components. In analyzing a structure for the movement due to earthquake, the movement components are usually considered asynchronous and separately; while, the precise analysis of a structure under seismic load needs considering all movement components simultaneously. In recording and evaluating earthquake movements only three perpendicular transmission movement components are measured and among those components, two horizontal components are usually taken into consideration [10,11]. According to investigations it was realized that for short periods and in distances near fault, the effect of earthquake vertical component was high and sometimes it was more than horizontal components [12]. The observations and investigations of recent earthquakes show the importance of earthquake vertical component in caused damages and destructions [13].

In the present study, due to the importance and necessity of the vertical component of earthquake and also due to coupled motions of horizontal and vertical components of earthquake, the proposed isolator by Barghian and Shahabi [3] was investigated under vertical and horizontal components.

\section{Motion Differential Equation}

The Graizer and Kalkan [10] studied the equations of motion of single degree of freedom oscillator under the excitation of earthquake for different components. According to Fig. 5, a SDOF system is represented by a rigid bar and system flexibility is lumped in a rotational spring at the base.

When the system is subjected to an oscillation at the base by horizontal and vertical loads simultaneously and the weight is also considered, the horizontal motion equation may be obtained for a single degree of freedom system with mass $m$, stiffness $k$ and damping $c$, by taking moments about the base as follows:

$$
\begin{gathered}
m \ddot{u} l+c \dot{u} l+k u l-m\left(g-\ddot{v}_{g}\right) u=-m \ddot{u}_{g} l \\
m \ddot{u}+c \dot{u}+\left(k-\frac{m}{l}\left(g-\ddot{v}_{g}\right)\right) u=-m \ddot{u}_{g} \\
m \ddot{u}+c \dot{u}+\left(k-k_{G}^{\prime}\right) u=-m \ddot{u}_{g}
\end{gathered}
$$

where $u$ is the relative displacement of the pendulum with respect to ground. The connecting rod is assumed to be rigid. In this research, it is assumed that geometric stiffness amount of system is variable and is a function of earthquake vertical acceleration. As a result, the effective stiffness of the system is a time-dependent variable.

To derive the motion equation of one-degree of freedom model for the studied isolator under earthquake vertical and horizontal components, a model of single damper with mass-spring was considered. In this paper the assumptions which were made by Barghian and Shahabi [3] have been used.

Also, the following assumptions are used for equations:

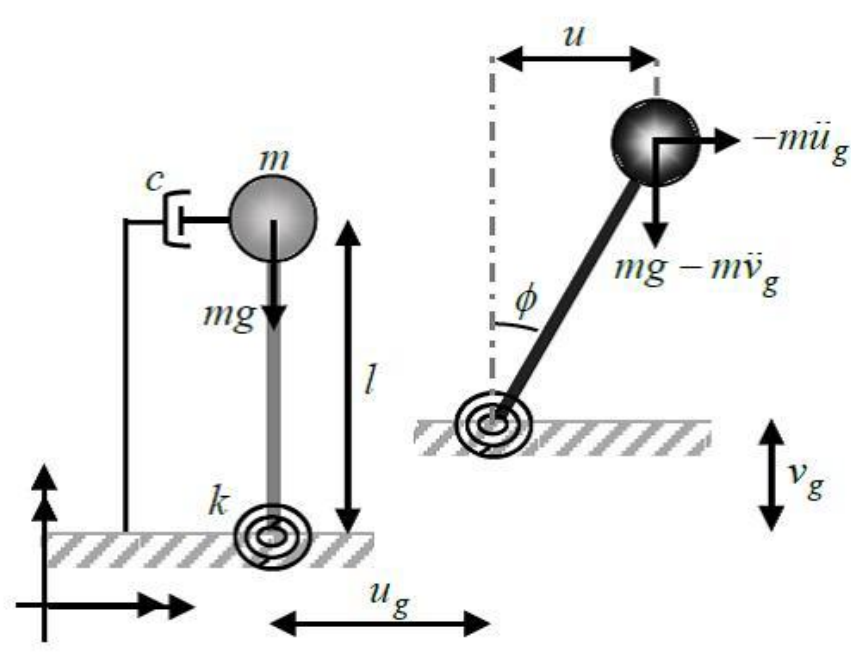

Fig. 5. Pendulum with a rigid rod

1 Columns are rigid and only the stiffness of bases is calculated.

2 Base mass is ignored compared with the structure mass.

3 There is sufficient friction between base and foundation so that the two surfaces do not slide against each other during movement.

4 Rolling friction between spherical surface and base (both are made of steel is ignored.

5 Each base Arm is rigid and there is no axial, bending, shear or torsional deformation.

6 The radius of the spherical surface is not very big.

The origin of axes is chosen as the contact point of base and foundation. As seen in Fig. 6, three different situations can be assumed.

First, a base is in equilibrium state (Fig. 6a). Second, the base has been rotated to the angle of $\theta_{0}$ and has been kept in that situation (Fig. 6p). Finally, the base has been released from the second position, where it will oscillate (Fig. 6). In this case the base will have the rotation angle of $\theta$. As a result, the contact point of base and foundation will have a displacement of $u=r \theta$ related to the origin point, where $r$ is base spherical radius [3]. Here, $u$ equals to the arc length of the arm end until the contact point of base with the ground. It is assumed that there is no slide between the base and foundation. In this situation, if the base is rotated to the angle of $\theta$ then the coordinate of structure mass which is assumed at the end of base will be as follows:

$$
\begin{aligned}
& x=u-b \sin \theta \\
& y=r-b \cos \theta
\end{aligned}
$$

where $b$ is the distance between the center of the sphere to the end of the arm (from center to base mass location) (see Fig. 6). Differentiating Eqs. (4) and (5) gives velocity at any time, t:

$$
\dot{x}=\dot{u}-b \dot{\theta} \cos \theta
$$




$$
\dot{y}=b \dot{\theta} \sin \theta
$$

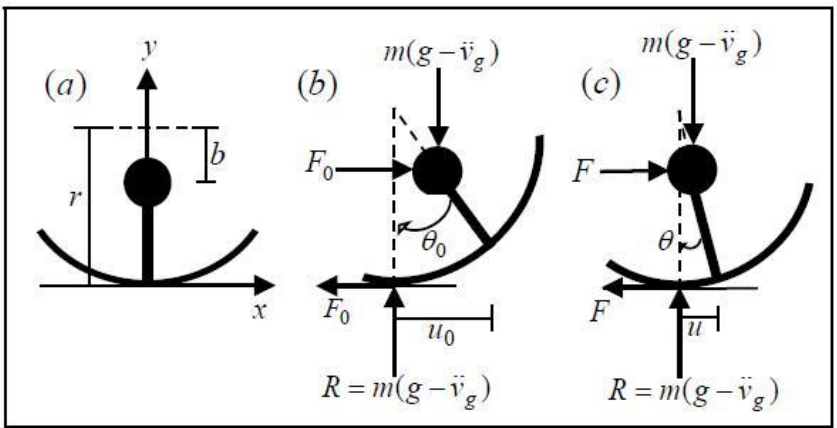

Fig. 6. Different situations of base: (a) equilibrium state; (b) rotation of $\theta_{0}$; and (c) oscillation state

The effect of earthquake vertical component may be applied by applying the vertical component of earthquake on potential energy. If it is supposed that there is no energy loss in the system, then, the whole system energy for the case (b) and (a) are equal. Therefore it can be said that the system kinetics energy at any time $t$ is equal to the lost energy under reduced mass height from the initial rotation of $\theta_{0}$. By this assumption the following equation can be written:

$$
\frac{1}{2} m v^{2}=m\left(g-\ddot{v}_{g}\right)\left(b \cos \theta-b \cos \theta_{\circ}\right)
$$

In which $\mathrm{v}$ is the structure mass movement velocity and, $\ddot{v}_{g}$ is the vertical acceleration of earthquake. If the velocity is decomposed to two components of horizontal and vertical, it can be written as:

$$
v^{2}=\dot{x}^{2}+\dot{y}^{2}
$$

With substituting the Eq. (9) in Eq. (8) it can be written as:

$$
\frac{1}{2} m\left(\dot{x}^{2}+\dot{y}^{2}\right)=m\left(g-\ddot{v}_{g}\right)\left(b \cos \theta-b \cos \theta_{\circ}\right)
$$

With differentiating the equation $\theta=u / r$ with respect to time, the following equation can be written:

$$
\dot{\theta}=\frac{\dot{u}}{r}
$$

By substituting $\dot{x}, \dot{y}, \theta$ and $\dot{\theta}$ in the Eq. $(10)$ and by simplifying the equations, the following equations can be written:

$$
\begin{gathered}
\frac{1}{2} m\left[\left(\dot{u}-b \frac{\dot{u}}{r} \cos \frac{u}{r}\right)^{2}+\left(b \frac{\dot{u}}{r} \sin \frac{u}{r}\right)^{2}\right]= \\
=m\left(g-\ddot{v}_{g}\right)\left(b \cos \frac{u}{r}-b \cos \frac{u_{\circ}}{r}\right) \\
\frac{1}{2} m\left[\left(\dot{u}^{2}-2 b \frac{\dot{u}^{2}}{r} \cos \frac{u}{r}+\frac{b^{2} \dot{u}^{2}}{r^{2}} \cos ^{2} \frac{u}{r}\right)+\left(b^{2} \frac{\dot{u}^{2}}{r^{2}} \sin ^{2} \frac{u}{r}\right)\right]= \\
-m\left(g-\ddot{v}_{g}\right) b\left(\cos \frac{u}{r}-\cos \frac{u_{\circ}}{r}\right)
\end{gathered}
$$

$$
\begin{aligned}
& \dot{u}^{2}-2 b \frac{\dot{u}^{2}}{r} \cos \frac{u}{r}+b^{2} \frac{\dot{u}^{2}}{r^{2}}= \\
& =2\left(g-\ddot{v}_{g}\right) b\left(\cos \frac{u}{r}-\cos \frac{u_{\circ}}{r}\right)
\end{aligned}
$$

where $u_{\circ}$ is the initial displacement of base and foundation contact point of the origin of the coordinate due to $\theta_{\circ}$ rotation (as shown in Fig. 6p). Differentiating Eq. (14) with respect to time $t$ will give the system differential motion equation:

$$
\begin{gathered}
2 \ddot{u} \dot{u}-2 \frac{b}{r}\left(2 \ddot{u} \dot{u} \cos \frac{u}{r}-\dot{u}^{2} \frac{\dot{u}}{r} \sin \frac{u}{r}\right)+2 \frac{b^{2}}{r^{2}} \ddot{u} \dot{u}= \\
=-2\left(g-\ddot{v}_{g}\right) b \frac{\dot{u}}{r} \sin \frac{u}{r} \\
\ddot{u}\left(r+\frac{b^{2}}{r}-2 b \cos \frac{u}{r}\right)+\dot{u}^{2} \frac{b}{r} \sin \frac{u}{r}+ \\
+\left(g-\ddot{v}_{g}\right) b \sin \frac{u}{r}=0 \\
\ddot{u}+\frac{\dot{u}^{2} b}{r^{2}+b^{2}-2 r b \cos \frac{u}{r}} \sin \frac{u}{r}+ \\
+\frac{\left(g-\ddot{v}_{g}\right) b}{r+\frac{b^{2}}{r}-2 b \cos \frac{u}{r}} \sin \frac{u}{r}=0
\end{gathered}
$$

Eq. (17) represents the free vibration motion equation of the system under the effect of earthquake vertical component. In order to apply horizontal acceleration, the force $-m \ddot{u}_{g}$ is added to the right hand side of Eq. (17). Due to the fact that the unit of the equation on left hand side is not similar to the added force, the left hand side of the equation is multiplied by $m$. When the

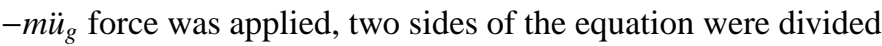
by $m$. The Eq. (18) was obtained:

$$
\begin{aligned}
& \ddot{u}+\frac{\dot{u}^{2} b}{r^{2}+b^{2}-2 r b \cos \frac{u}{r}} \sin \frac{u}{r}+ \\
& +\frac{\left(g-\ddot{v}_{g}\right) b}{r+\frac{b^{2}}{r}-2 b \cos \frac{u}{r}} \sin \frac{u}{r}=-\ddot{u}_{g}
\end{aligned}
$$

where $\ddot{u}_{g}$ is the horizontal acceleration of earthquake, $\ddot{v}_{g}$ is the vertical acceleration of earthquake, $b$ is the distance between the center of sphere to the center of mass, $r$ is base spherical radius, $\ddot{u}$ is the acceleration of isolator, $\dot{u}$ is the motion speed of isolator and $u$ is the displacement of isolator. In this study, first the equation of motion for the isolator was solved under horizontal earthquake acceleration by using MATLAB software. This was carried out for damping ratio $\xi=0.02$ and various amounts of $r$ and $b$ parameters. At this stage the Eq. (19) and Northridge earthquake acceleration were used.

$$
\begin{aligned}
& \ddot{u}+\frac{\dot{u}^{2} b}{r^{2}+b^{2}-2 r b \cos \frac{u}{r}} \sin \frac{u}{r}+ \\
& +\frac{g b}{r+\frac{b^{2}}{r}-2 b \cos \frac{u}{r}} \sin \frac{u}{r}=-\ddot{u}_{g}
\end{aligned}
$$


By solving the Eq. (19) numerically, Figs.7 to 10, were drawn. Different earthquakes were used and compared with the results of Barghian and Shahabi. Here only the results of Northridge are shown in the Figs. 7 to 10 The Results were the same as Barghian and Shahabi's results [3]. $r$ value was started from $50 \mathrm{~cm}$ and was increased by the value of growth $25 \mathrm{~cm}$ until it reached to $200 \mathrm{~cm}$. Only four of graphs are represented in this paper as a sample. Also, by solving the Eq. (18) numerically, Figs. 11 to 16 were drawn for various $r$ and $b$ parameters. The graphs refer to displacement spectral response and spectra pseudo-acceleration response for Kobe, Imperial Valley and Northridge of earthquakes. The comparison of the results of solving the differential equation numerically under earthquake horizontal component effect and the results of solving the differential equation under the horizontal and vertical components combined effects of earthquake for Northridge earthquake are shown in Figs. 17 to 22. The Eqs. (18) and (19) were solved by using Newmark- $\beta$ step by step time integration method.

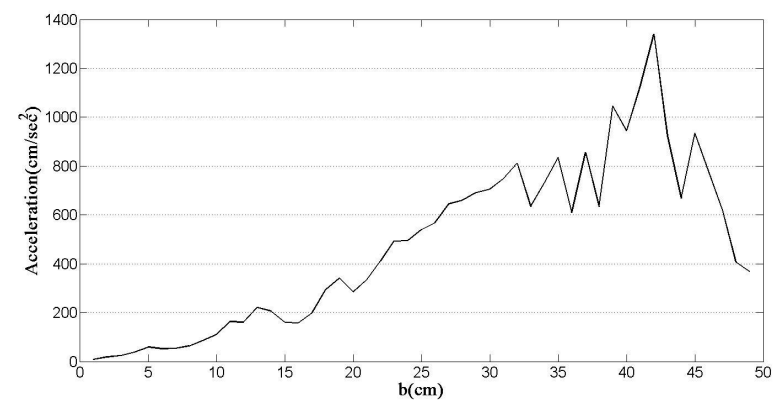

Fig. 7. Pseudo-acceleration-b response spectrum $[r=50 \mathrm{~cm}$ under horizontal component of earthquake]

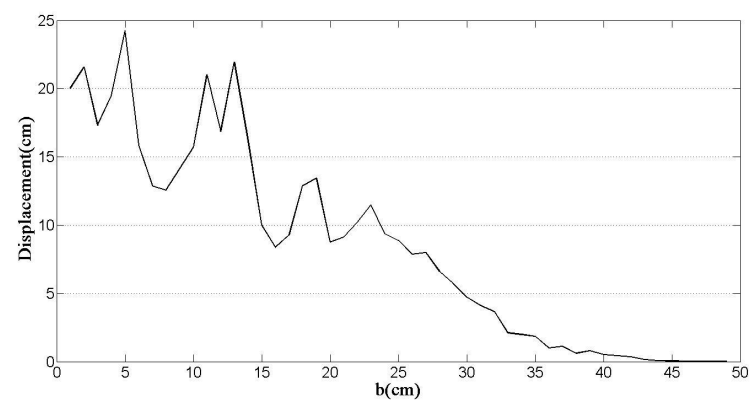

Fig. 8. Displacement-b response spectrum $[r=50 \mathrm{~cm}$ under horizontal component of earthquake]

\section{Discussion}

The equations of motion were solved numerically for horizontal acceleration component only and for horizontal and vertical acceleration components simultaneously.

The results of Imperial Valley and Northridge earthquakes showed that: the maximum displacement of the isolator occurs when $b$ has the minimum value (see Figs. 8, 10, 12, 14 and 16. Increasing the value of $b$ causes the reduction in displacement which undergoes an irregular oscillation. The irregularity continues uniformly and finally reaches to zero when the amount

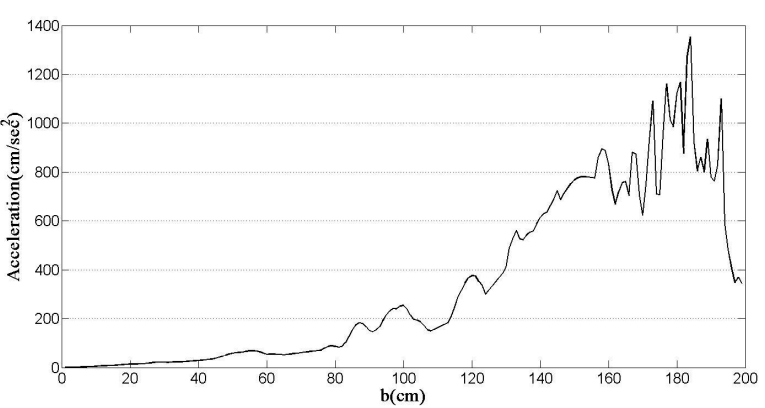

Fig. 9. Pseudo-acceleration-b response spectrum $[r=200 \mathrm{~cm}$ under horizontal component of earthquake]

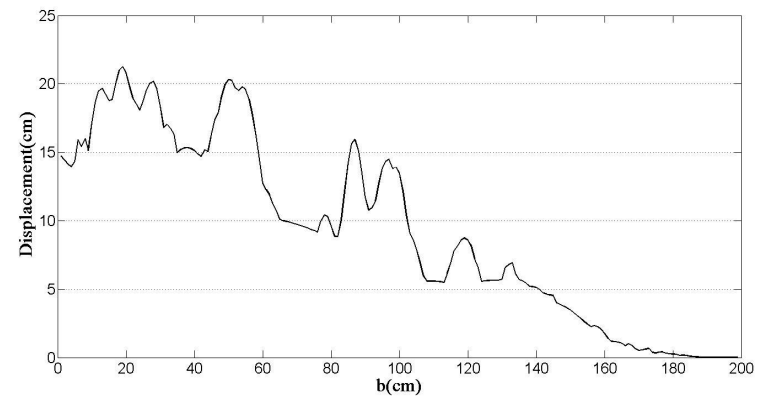

Fig. 10. Displacement-b response spectrum $[\mathrm{r}=200 \mathrm{~cm}$ under horizontal component of earthquake]

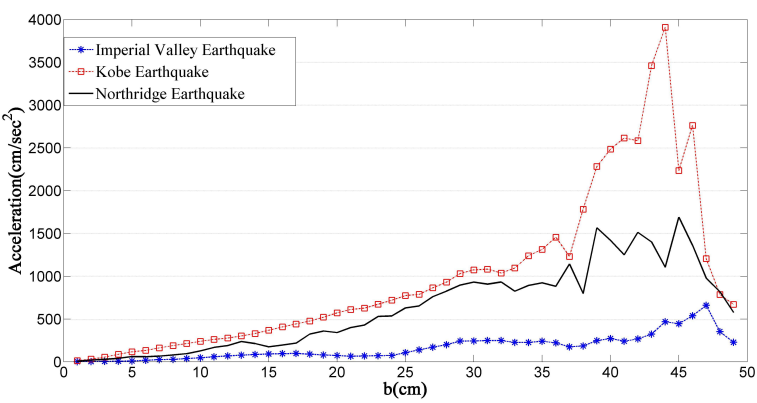

Fig. 11. Pseudo-acceleration-b response spectrum $[r=50 \mathrm{~cm}$ under horizontal and vertical components combined effect of earthquake]

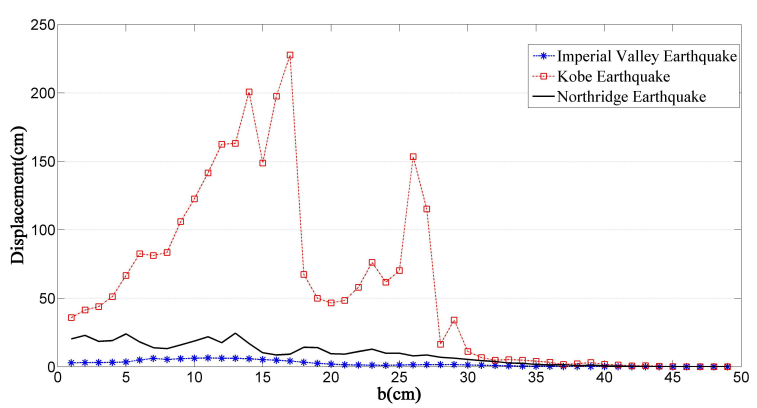

Fig. 12. Displacement $-\mathrm{b}$ response spectrum $[r=50 \mathrm{~cm}$ under horizontal and vertical components combined effect of earthquake] 


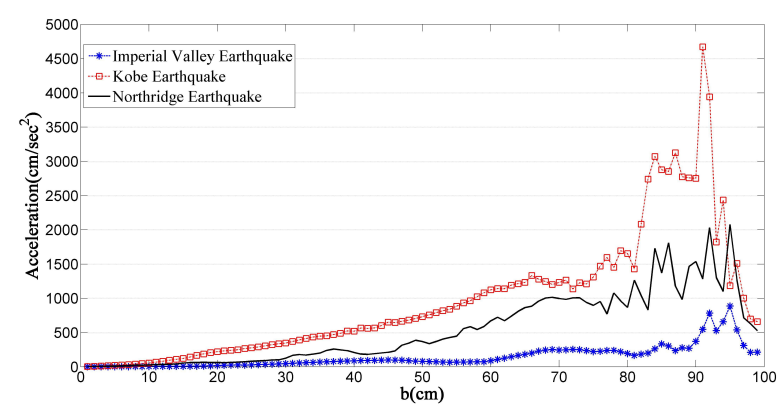

Fig. 13. Pseudo-acceleration-b response spectrum $[r=100 \mathrm{~cm}$ under horizontal and vertical components combined effect of earthquake]

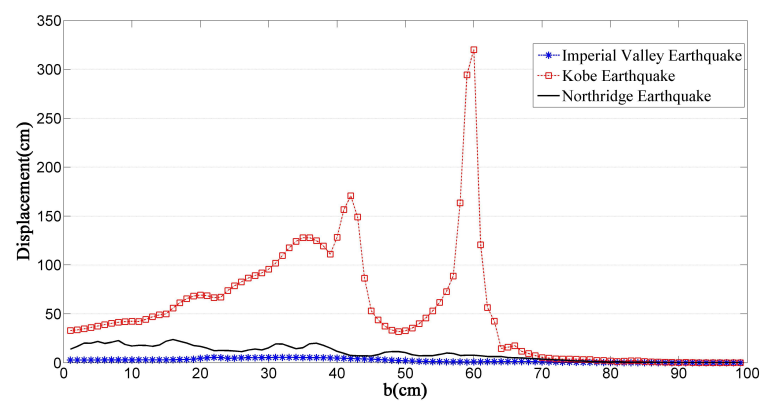

Fig. 14. Displacement-b response spectrum $[r=100 \mathrm{~cm}$ under horizontal and vertical components combined effect of earthquake]

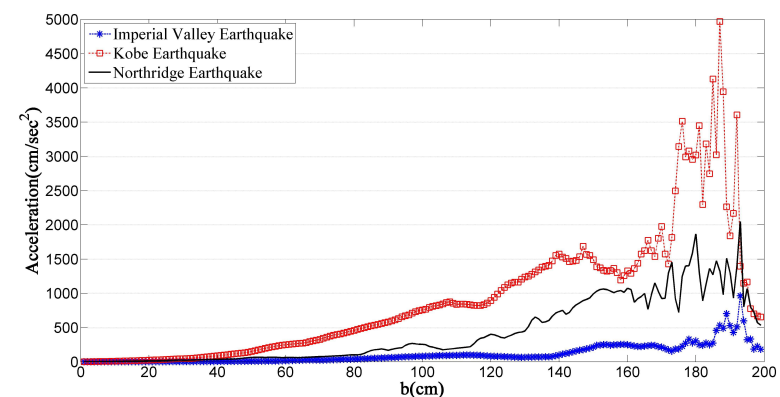

Fig. 15. Pseudo-acceleration-b response spectrum $[r=200 \mathrm{~cm}$ under horizontal and vertical components combined effect of earthquake]

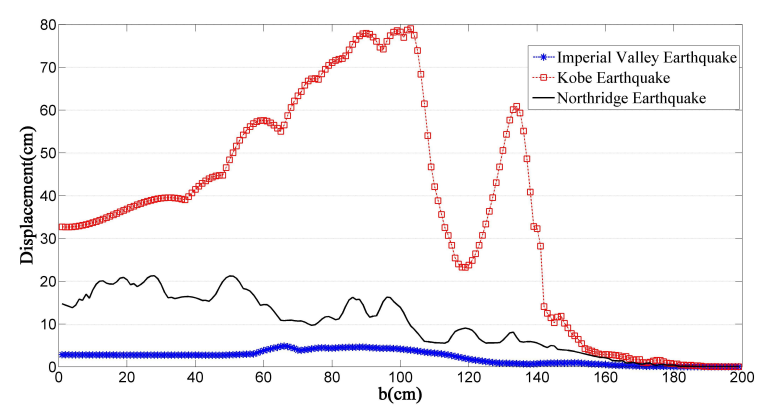

Fig. 16. Displacement-b response spectrum $[r=200 \mathrm{~cm}$ under horizontal and vertical components combined effect of earthquake]

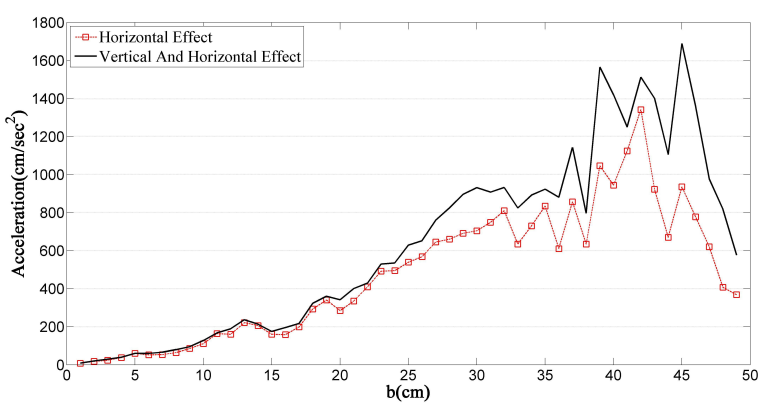

Fig. 17. Pseudo-acceleration-b response spectrum $[r=50 \mathrm{~cm}]$

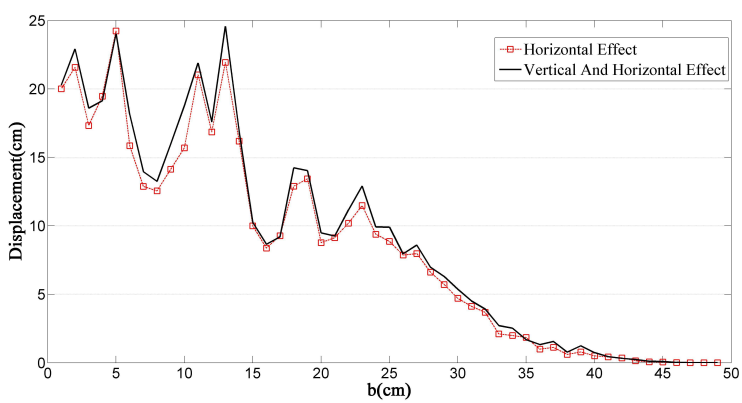

Fig. 18. Displacement $-\mathrm{b}$ response spectrum $[r=50 \mathrm{~cm}]$

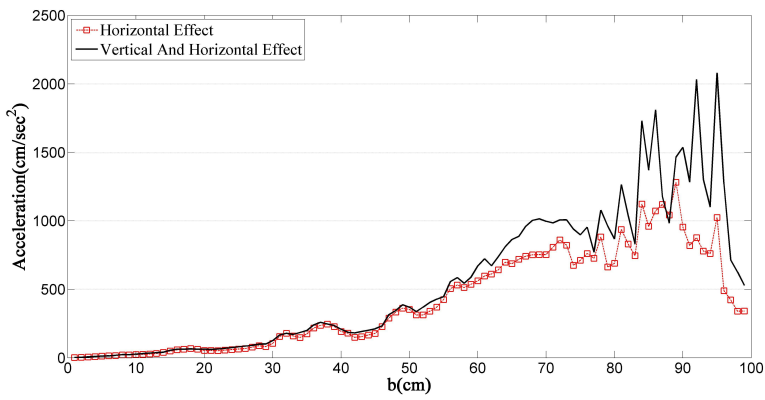

Fig. 19. Pseudo-acceleration-b response spectrum $[r=100 \mathrm{~cm}]$

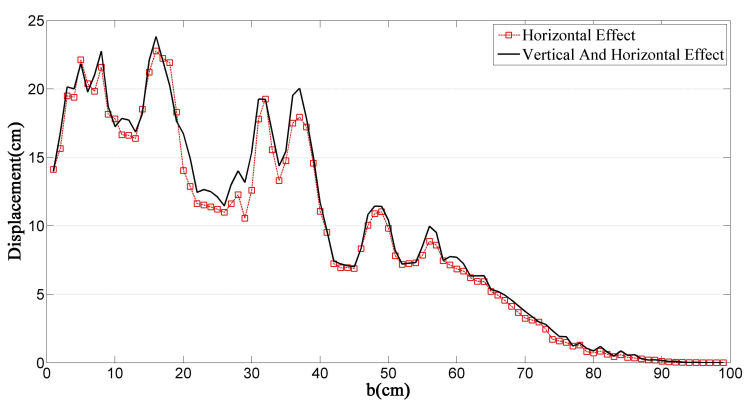

Fig. 20. Displacement-b response spectrum $[r=100 \mathrm{~cm}]$

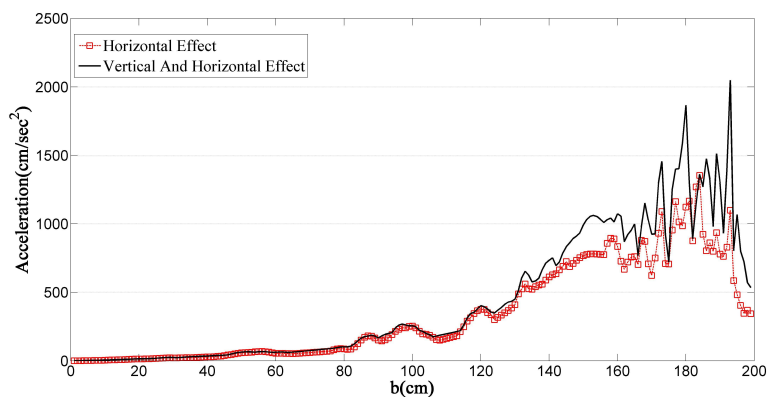

Fig. 21. Pseudo-acceleration-b response spectrum $[r=200 \mathrm{~cm}]$ 


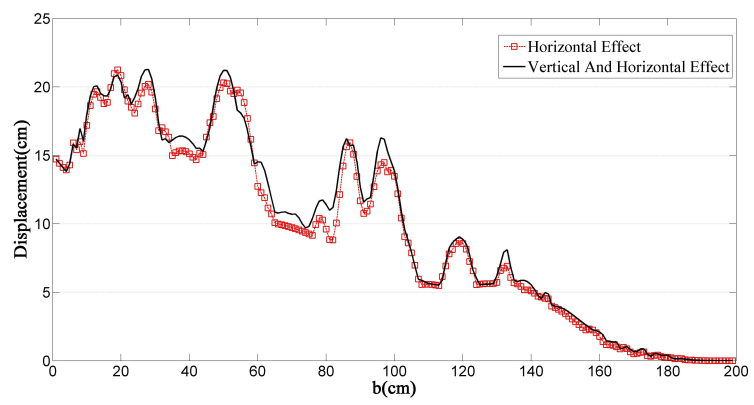

Fig. 22. Displacement-b response spectrum $[r=200 \mathrm{~cm}]$

of $b$ reaches to its maximum value. This is similar to the situation in which the structure has been isolated from ground and there is no motion applied from ground to the structure. Also, when $b$ has maximum value, the isolator displacement tends towards zero. This means that the structure has been attached to ground completely and all ground movement is transferred to structure. The above explanations can be described about Kobe earthquake results when vertical and horizontal acceleration components are applied simultaneously (see Figs. 12, 14 and 16; but in this case the irregularity is high. This irregularity is about in the range of $b / r=0.15$ and $b / r=0.7$. The isolator displacement for Kobe earthquake is high. Therefore, it is better to study more about the isolator displacements under earthquakes with high horizontally acceleration.

From results, it was considered that when $b$ tends to zero the amount of acceleration applied to the isolator tends to zero. The acceleration is increased when $b$ is increased. The increasing continues regularly until where the increasing becomes irregular at the end of the graph. Finally, the amount of acceleration is somehow reduced when $b$ reaches the maximum value. This reduction is not much that one can ignore the increasing of most part of the graph. When $b=0$, the acceleration in isolator is zero and the displacement is maximum. This means that in this case, the structure has been totally isolated from ground and that ground accelerations are not applied to the structure. If the irregularity at the end of the graph is ignored, it can be said that for high amounts of $b$, the structure has stuck to the ground and ground acceleration is transferred to the structure (see Figs. 7, 9, 11, 13 and 15,

From Figs. 17 to 22 which are related to Northridge earthquake, it can be considered that the effect of vertical component on the isolator horizontal response is not much. It may be interpreted that as the base arm is rigid, therefore, ground vertical acceleration effects only gravitational acceleration. The differences in graphs could be high if the base arm was not rigid.

In the graphs, ground vertical acceleration has somehow increased the isolator pseudo-acceleration response and displacement response.

The amount of $b$ should be chosen suitably in order to satisfy both structure displacement and acceleration. $b$ value should not be very small because the structure moves freely under even small lateral load, hence the structure becomes unstable. For this purpose, it is better to determine the isolator response spectrums for specific earthquakes and then choose $b$ value based on them. In this study, different values were adopted for $r$ to observe the effect of $r$ on structure response; and diagrams were plotted based on different $r$ 's. By increasing $r$, isolator acceleration response is reduced for a specific value of $b / r$. This was found to be true for both horizontal and vertical together with horizontal earthquake components. In this paper $b / r=0$ to $b / r=0.5$ were considered. Choosing bigger values for $r$ is useful. From Fig. 6 it is seen that if the base is rotated by $\pi$ radians or more, there will be unstable situation for the system. So $r$ should be chosen big enough that the maximum base displacement would not reach to the mentioned rotation.

\section{Conclusions}

1 In this study a new approach of base isolation method has been studied under vertical and horizontal earthquake components simultaneously. Results showed that this method is effective on reducing horizontal earthquake effect on the structure. For this purpose by choosing $b$ and $r$ values, maximum applied acceleration on the structure and the structure displacement can be controlled. In other words, for a specific value of $r$, the more reduction in $b$, the smaller acceleration is applied to the structure. Also, $b$ value should not be chosen very small because in this case, the isolator will move under even small lateral loads and hence it will be unstable. By increasing $r$ value, the structure acceleration can be reduced. In other words, by increasing $r$ and keeping the ratio $b / r$ constant, the applied acceleration to the structure is reduced. However, $r$ value should be chosen rationally and economic considerations should be considered. It was found from the graphs that the ration $b / r$ should be less than 0.5 .

2 For each amount of $r$, there is a critical displacement so that if the bases are displaced to that amount, the structure will be unstable. This displacement amount is equal to $\pi$.r (for going and returning).

3 The results for item 1 were obtained fore Imperial Valley and Northridge earthquakes under vertical and horizontal earthquake acceleration, but when the $b$ amount is close to $r$, the irregularity in pseudo-acceleration spectrum diagram is seen. Therefore, the $b$ amount should not be chosen close to $r$ amount. For Kobe earthquake, the irregularity is high for both displacement spectrum and pseudo-acceleration spectrum. The reason is that the horizontal acceleration for this earthquake is high. Therefore, for earthquakes with high acceleration more study should be carried out.

4 The results showed that earthquake vertical acceleration caused increasing on the isolator acceleration response and finally caused increasing on the structure acceleration. 


\section{References}

1 Naeim F, Kelly JM, Design of seismic isolated structures, Wiley, (1993).

2 Skinner RI, Robinson WH, Mc Verry GH, An introduction to seismic isolation, Wiley, (1993).

3 Barghian M, Shahabi AB, A new approach to pendulum base isolation, Structural Control and Health Monitoring, 14, (2007), 177-185, DOI 10.1002/stc.115

4 Lu LY, Hsu CC, Experimental study of variable-frequency rocking bearings for near-fault seismic isolation, Engineering Structures, 46, 116-129, DOI 10.1016/j.jsv.2012.12.008

5 Lu LY, Lin GL, Lin CC, Absolute-energy-based active control strategies for linear seismic isolation systems, Structural Control and Health Monitoring, 18(3), (2011), 321-340, DOI 10.1002/stc.373

6 Sylvain C, MacRae GA, Rodgers GW, Chase JG, Nonlinear design and sizing of semi-active resettable dampers for seismic performance, Engineering Structures, 39(3), (2012), 139-147, DOI 10.1016/j.engstruct.2012.01.015

7 Fenz DM, Constantinou MC, Spherical sliding isolation bearings with adaptive behavior: experimental verification, Earthquake Engineering Structural Dynamics, 37(2), (2008), 185-205, DOI 10.1002/eqe.750

8 Ismail M, Rodellar J, Carusone G, Domaneschi M, Martinelli L, Characterization, modeling and assessment of Roll-N-Cage isolator using the cable-stayed bridge benchmark, Acta Mech., 224, (2013), 525-547, DOI 10.1007/s00707-012-0771-4

9 Domaneschi M, Martinelli L, Carusone G, Ismail M, Rodellar J, Seismic Protection of the ASCE Updated Cable-Stayed Bridge Benchmark with RNC Passive Devices, In: The 6th International Conference on Bridge Maintenance, Safety and Management (IABMAS 2012); Stresa, Italy.

10 Ichihashi I, Morinaka I, Minami Y, Koyanagi Y, Takeuchi Y, Hirama $\mathbf{T}$, Non- simultaneity and combination of horizontal and vertical earthquake response of PWR type nuclear reactor building, SMiRT-12 Elsevier Science, (1993).

11 Kusunoki K, Nakano Y, Okada T, The effect of vertical excitation on structural response seismic characteristics, Kobe earthquake, Japan, Report on the Jan. 17, (1995).

12 Graizer V, Kalkan E, Multi-component ground motion response spectra for coupled horizontal, vertical, angular accelerations and tilt, SET Journal of Earthquake Technology, 44(1), (2007), 259-284. Paper No. 485.

13 Jig KS, Elnashai AS, eismic assessment of RC structures considering vertical ground motion, 2008. MAE center report; No. 08-03. 